\title{
Aplikasi Penerimaan Siswa Baru (PSB) Berbasis Web Pada SDIT Yasir Cipondoh
}

\author{
Puji Catur Siswipraptini $^{1}$; Riki Ruli A. Siregar ${ }^{2}$; Rahma Farah Ningrum ${ }^{3}$ \\ 1, 2, 3 Institut Teknologi PLN \\ 1 pujicatur@itpln.ac.id
}

\begin{abstract}
SDIT Yasir is an Islamic elementary school located in Cipondoh, Tangerang. The Web-Based New Student Admission was created to make prospective students easier to register the school and to manage data student easily for school. Users of this application are prospective students and the registration part at SDIT Yasir. There are 5 menus available on this application, namely registration, check email, payment, payment verification and change payment data.
\end{abstract}

Keywords: Application, Web Based, Prospective Student

\section{ABSTRAK}

SDIT Yasir adalah sekolah dasar berbasis Islam yang terletak di Cipondoh Tangerang. Aplikasi Penerimaan Siswa Baru berbasis Web dibuat untuk memudahkan calon siswa mendaftar pada sekolah dan kemudahan untuk mengelola data siswa bagi sekolah. Pengguna dari aplikasi ini adalah calon siswa dan bagian registrasi pada SDIT Yasir. Ada 5 menu yang tersedia pada aplikasi ini yaitu pendaftaran, cek email, pembayaran, verifikasi pembayaran dan ubah data pembayaran.

Kata kunci: Aplikasi, Berbasis Web, Pendaftaran Siswa Baru 


\section{PENDAHULUAN}

Yayasan Pendidikan Ibnu Rusydi (YASIR) adalah sebuah Yayasan yang berkecimpung di dunia pendidikan berbasis Islami. Yasir Foundation memiliki 3 unit pendidikan yaitu TK, SDIT dan SMP yang beralamat di Jalan Maulana Hasanudin No. 43, Cipondoh Makmur Kota Tangerang. Fasilitas yang dimiliki salah satu nya oleh SDIT Yasir, yaitu ruang kelas sebanyak 20 dengan jumlah rombongan belajar sebanyak 19, laboratorium dan perpustakaan sebanyak 1, sementara jumlah guru sebanyak 31 guru dan siswa sebanyak 508 (kemdikbud.go.id). SDIT Yasir menerapkan kurikulum K-13 dalam pembelajarannya, dengan akreditasi sekolah "A" dan terdaftar sebagai anggota Jaringan Sekolah Islam Terpadu (JSIT) dengan nomor sertifikat 02/sa/JSIT/VI/2016 No. Reg 3.01.71.02.005. Selain itu SDIT Yasir menerapkan metode khusus pemahaman bahasa Arab Al-Qur'an "Metode Ummi", Pembelajaran berbasis projek (Project Based Learning) dan fasilitas kelas yang diajarkan oleh 2 (dua) guru untuk kelas I, II dan III (sekolahyasir.id).

Penggunaan system berbasis web sudah banyak di gunakan di berbagai bidang, diantaranya implementasi pada pemantauan dan peramalan ganggang ber bahaya di pantai [1], karakteristik gerakan tanah pada lempeng bumi [2], system pendukung keputusan untuk manajemen irigasi [3] dan tentu saja dalam bidang Pendidikan [4]. Sistem Informasi Mahasiswa (SIS) adalah jenis Sistem Informasi (SI), dan juga dikenal sebagai Sistem Manajemen Siswa, Perangkat Lunak Administrasi Sekolah, dan Sistem Administrasi Siswa [5]. SIS dapat digunakan untuk membantu pengguna dengan menyediakan manajemen catatan kronologis di berbagai bidang seperti penyelidikan, aplikasi, pendaftaran, kinerja akademik, dan sejarah, dan juga memungkinkan pengguna untuk memfasilitasi manajemen penagihan dan biaya, untuk memproses acara penting seperti wisuda dan ujian, hingga kelas program, dan untuk melaporkan masalah operasional dan manajemen diantara yang lain.

Beberapa sekolah sudah menerapkan penerimaan siswa baru melalu Sistem Informasi Berbasis Web yang salah satu manfaatnya untuk meningkatkan Mutu Pendidikan. Siswa diberikan beberapa kemudahan diantaranya untuk melihat informasi tentang sekolah dan melakukan pendaftaran. Pihak sekolah pun terbantu dengan ada nya system ini yaitu mengelola data siswa dan membuat laporan perkembangan pendaftaran siswa [6]. SMAN 1 Ulu Belu di Lampung sudah menerapkan aplikasi berbasis Mobile Penerimaan Siswa Baru, dan di anggap bisa mengatasi permasalahan pengolahan data siswa karena dilakukan dengan integrasi database sekolah [7].

\section{METODE/PERANCANGAN PENELITIAN}

\subsection{Contoh Persamaan Matematika}

Gambar 1 menunjukkan tahap pelaksanaan Program Kemitraan Masyarakat di SDIT Yasir, Kecamatan Cipondoh Kota Tangerang.

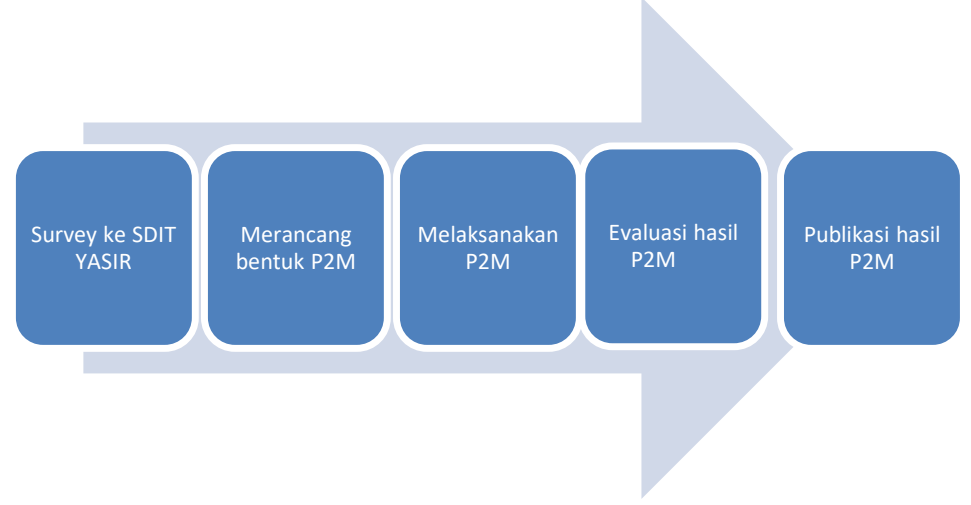

Gambar 1. Metode Pelaksanaan PKM di SDIT Yasir 
Pelaksanaan PKM diawali dengan melakukan survey ke tempat mitra untuk menggali kebutuhan mitra, ada 2 hal yang menjadi kebutuhan mitra saat itu yaitu pembuatan Aplikasi Penerimaan Siswa Baru dan pembuatan Sistem Informasi Keuangan. Pada penelitian ini akan dibahas mengenai pembuatan Sistem Informasi Penerimaan Siswa Baru dimana sebagai pengguna nya adalah calon siswa dan bagian pendaftaran sekolah. Tahap berikut nya adalah merancang tampilan antarmuka dari system, membuat program, melakukan sosialisasi dan implementasi.

\section{HASIL DAN PEMBAHASAN}

Usecase diagram dari sistem ini adalah seperti pada gambar 2 .

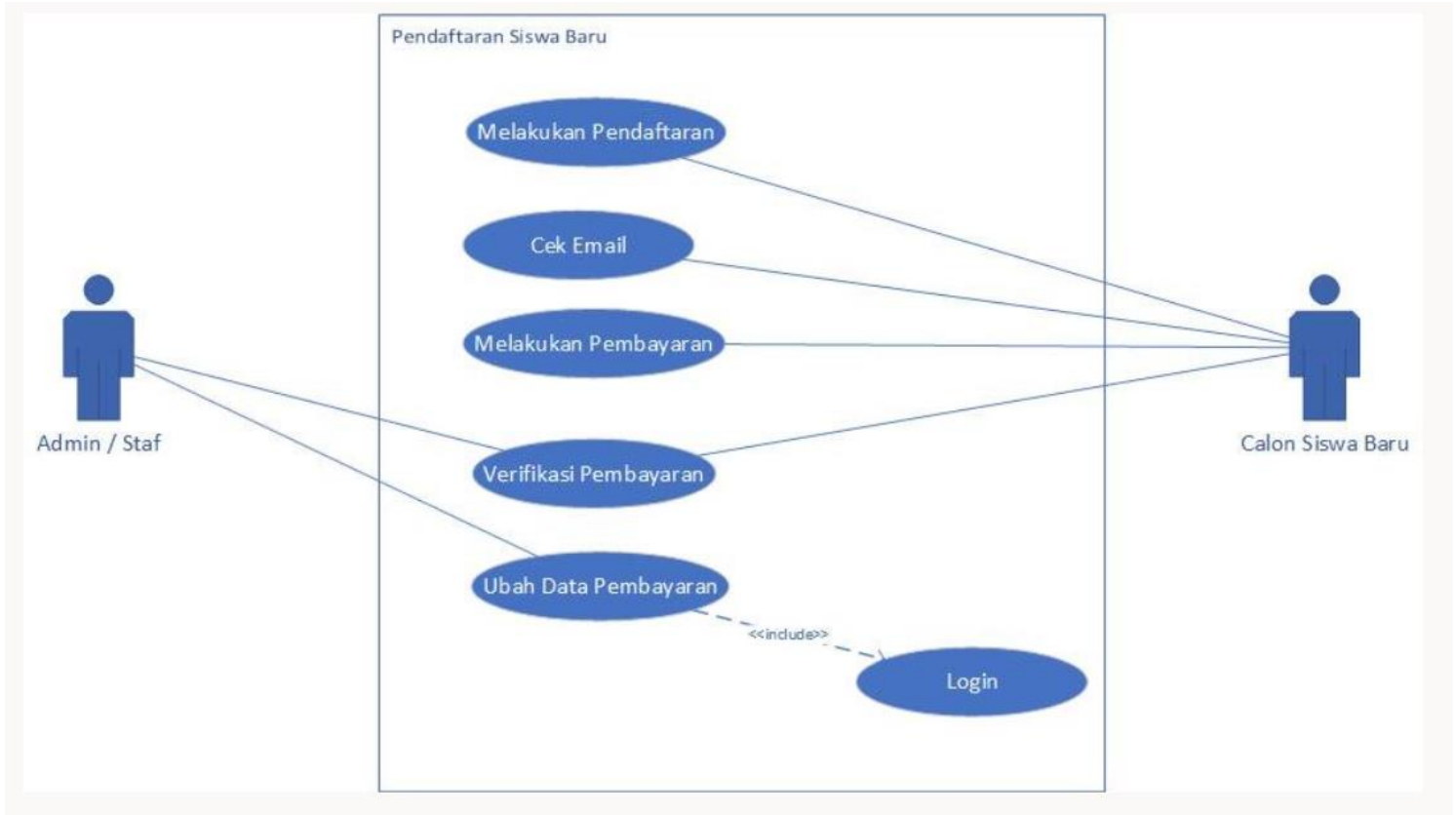

Gambar 2. Diagram Usecase Aplikasi Penerimaan Siswa Baru

Pada gambar 2 terlihat bahwa aplikasi ini memiliki 2 user yaitu Admin/Staf dan Calon Siswa Baru. Aktivitas Calon Siswa Baru dapat melakukan pendaftaran melalui system, melakukan cek email dari hasil pendaftaran, melakukan pembayaran dan melakukan verifikasi pembayaran. Sedangkan Admin dapat melakukan verifikasi pembayaran dan merubah data pembayaran. Berikut ini adalah tampilan antarmuka pada aplikasi:

\section{a) Form Pendaftaran Siswa Baru}

Calon orang tua siswa baru wajib mengisi formulir pendaftaran online dengan melengkapi informasi data diri calon siswa baru dan orangtua. 
Terang: Jurnal Pengabdian Pada Masyarakat Menerangi Negeri

e-ISSN: 2655-5948

Vol. 3, No. 1, Desember 2020

\section{Aplikasi Penerimaan Siswa Baru}

\section{Pendafataran}

Pengisian Formulir Pendafataran
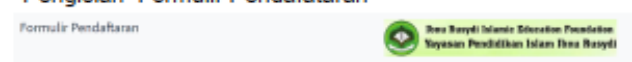

Klik "Submit" untuk daftar
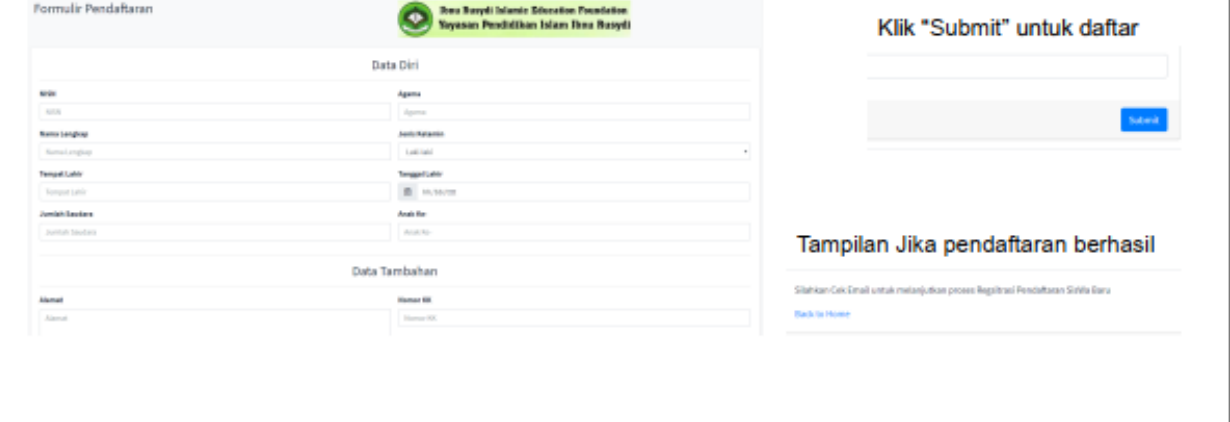

Gambar 3. Form Pendaftaran Siswa Baru

\section{b) Notifikasi Proses Pendaftaran via Email}

Setelah calon orang tua siswa baru mengisi formulir pendaftaran, maka sistem akan mengirimkan notifikasi pendaftaran siswa baru melalui email.

\section{Aplikasi Penerimaan Siswa Baru}

\section{Siswa Baru}

\section{Pendafataran}

Mendapatkan email pembayaran pendafataran

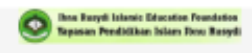

Dear
Wali dari 1

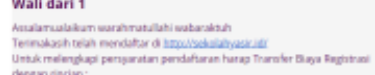

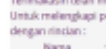
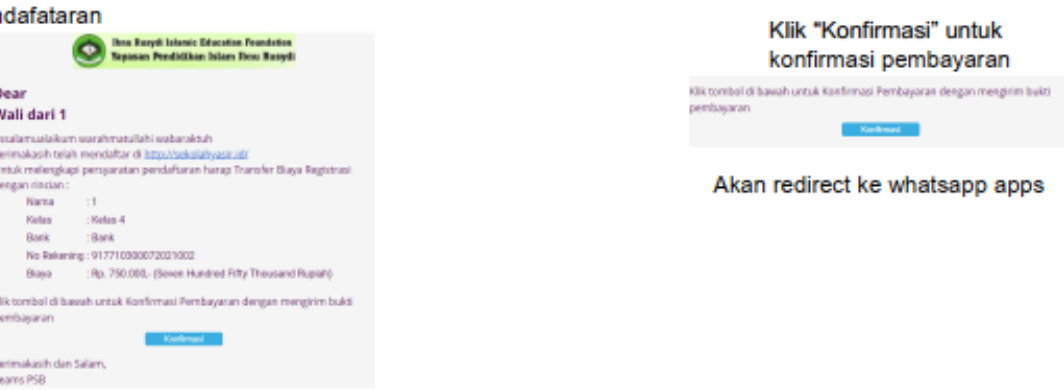

Akan redirect ke whatsapp apps

Gambar 4. Notifikasi proses pendaftaran melalui email

\section{c) Tampilan Login}

Gambar 5 berikut adalah proses login yang harus dilakukan oleh admin atau staff SDIT Yasir 


\section{Aplikasi Penerimaan Siswa Baru}

Login

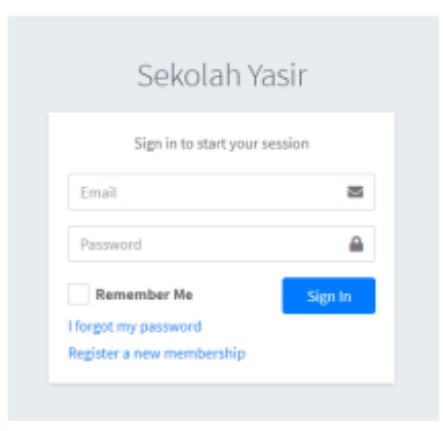

Form Login untuk admin dan staff

Gambar 5. Tampilan login admin atau staff

\section{d) Tampilan Dashboard}

Gambar 6 berikut adalah tampilan beranda/dashboard Sistem Informasi Penerimaan Siswa Baru setelah admin dan staff melakukan login.

\section{Aplikasi Penerimaan Siswa Baru}

\section{Admin/Staff}

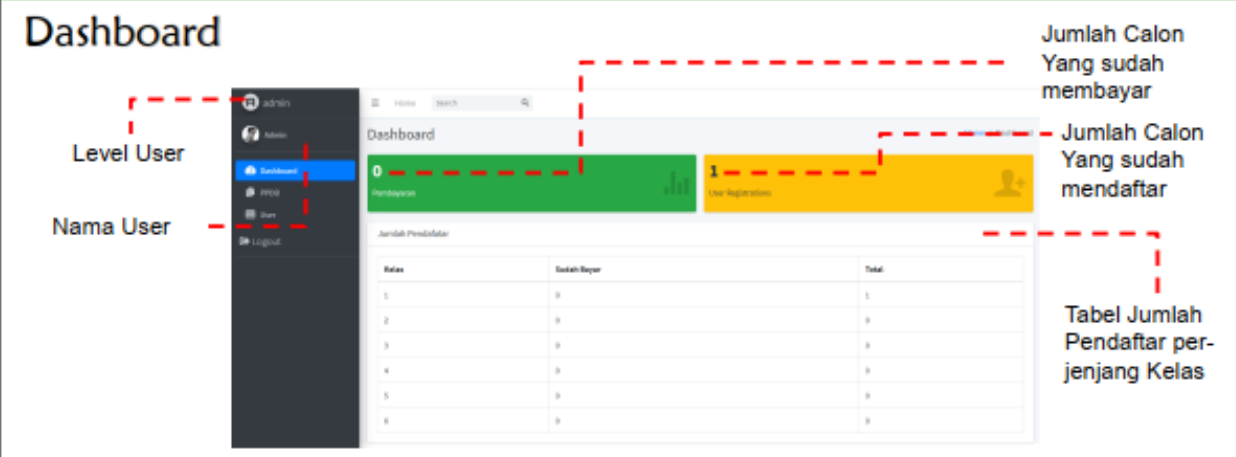

Gambar 6. Tampilan dashboard admin/staff

\section{e) Tampilan List Daftar Calon Siswa Baru}

Gambar 7 berikut adalah tampilan tabel daftar calon siswa baru. 


\section{Aplikasi Penerimaan Siswa Baru}

\section{Admin/Staff}

\section{Tabel PSB}

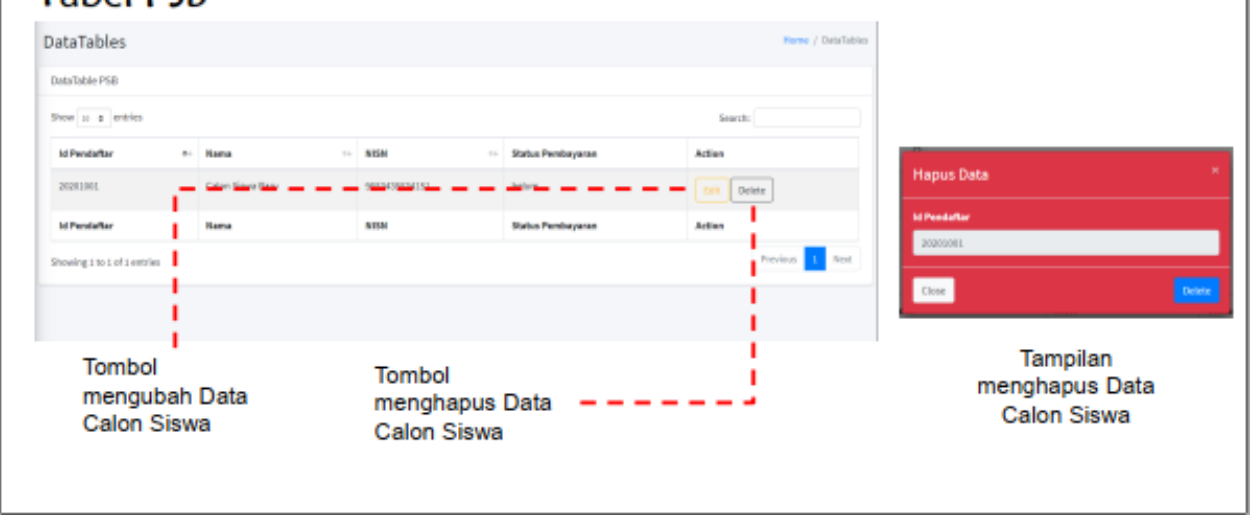

Gambar 7. Tampilan Daftar Calon Siswa Baru

\section{f) Tampilan Edit dan View Data Calon Siswa Baru}

Gambar 8 berikut adalah tampilan menu edit dan view data calon siswa baru. Menu ini hanya dapat diakses oleh admin dan staff sekolah.

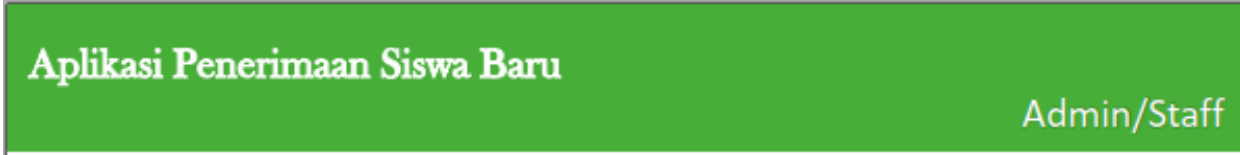

\section{Edit dan View Data}
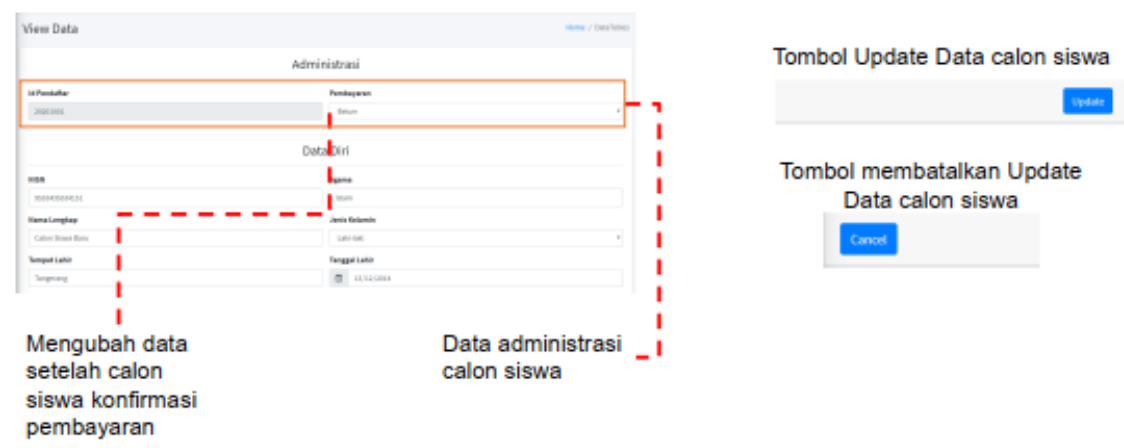

Gambar 8. Tampilan edit dan view data calon siswa baru

\section{g) Tampilan Data User}

Gambar 9 berikut adalah tampilan data user/pengguna yang dapat diakses oleh Admin sekolah. Admin dapat menambah, mengedit dan menghapus data user/pengguna aplikasi sistem Penerimaan Siswa Baru. 


\section{Aplikasi Penerimaan Siswa Baru}

\section{Admin/Staff}

\section{Tabel User}

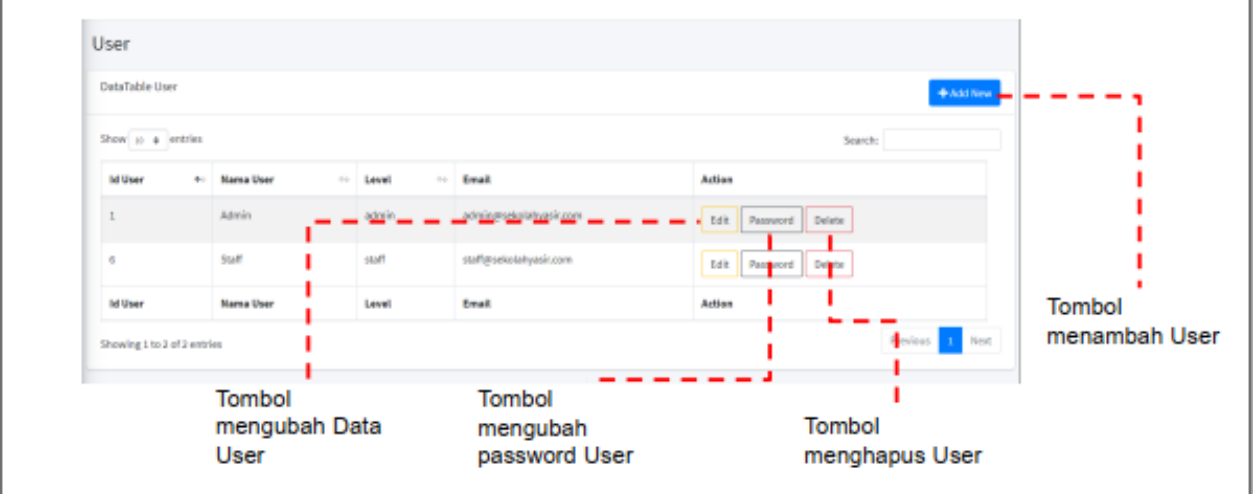

Gambar 9. Tampilan Data User

\section{KESIMPULAN}

Kerjasama antara tim PKM Fakultas Telematika Energi Institut Teknologi PLN dengan SDIT Yasir, Cipondoh Tangerang menghasilkan kegiatan pembuatan aplikasi penerimaan siswa baru dan pelatihan penggunaan aplikasi penerimaan siswa baru. Sosialisasi pembuatan system ini telah dilaksanakan terhadap mitra. Penerapan aplikasi ini diharapkan dapat membantu pihak sekolah untuk menjaring calon siswa baru dan memudahkan orangtua calon siswa baru untuk melakukan pendaftaran siswa baru tanpa harus datang ke sekolah.

\section{SARAN}

Sistem ini masih terus akan dilakukan perbaikan dan pendampingan terhadap mitra selama beberapa bulan ke depan.

\section{UCAPAN TERIMAKASIH}

Penulis mengucapkan terima kasih kepada Institut Teknologi PLN yang telah memberi dukungan yang membantu pelaksanaan pengabdian pada masyarakat ini.

\section{DAFTAR PUSTAKA}

[1] Y. Tian and M. Huang, "An integrated web-based system for the monitoring and forecasting of coastal harmful algae blooms: Application to Shenzhen city, China," J. Mar. Sci. Eng., vol. 7, no. 9, pp. 1-17, 2019.

[2] R. Klinc, Ž. Šebenik, M. Dolšek, M. Brozovič, and M. Dolenc, "A web-based system for the selection of characteristic ground motions,” Adv. Eng. Softw., vol. 135, no. September 2018, p. 102688, 2019.

[3] W. Wang, Y. Cui, Y. Luo, Z. Li, and J. Tan, "Web-based decision support system for canal irrigation management," Comput. Electron. Agric., vol. 161, no. September, pp. 312-321, 2019.

[4] D. Al-Fraihat, M. Joy, R. Masa'deh, and J. Sinclair, "Evaluating E-learning systems success: An empirical study," Comput. Human Behav., vol. 102, no. March 2019, pp. 67-86, 2020. 
[5] N. Maulidah, R. Pebrianto, R. Supriyadi, and A. Fauzi, "SISWA BARU DALAM MENINGKATKAN MUTU LEMBAGA PENDIDIKAN ( Studi Kasus : Mts Negeri Slawi Filial Di Sa Pecabean )," vol. 11, no. 4, 2019.

[6] D. Demirkol, C. Seneler, T. Daim, and A. Shaygan, "Measuring Emotional Reactions of University Students towards a Student Information System (SIS): A Turkish University Case," J. Knowl. Econ., vol. 62, no. October 2019, p. 101281, 2019.

[7] M. Muslihudin and M. A. Imamudin, "Pengembangan Aplikasi Penerimaan Siswa Baru Berbasis Web Mobile SMA Negeri 1 Ulu Belu," JATISI (Jurnal Tek. Inform. dan Sist. Informasi), vol. 5, no. 2, pp. 194-206, 2019. 